\title{
McDonaldization in Households
}

\author{
Jacob P. Woolridge a*, Leslie Stanley-Stevens ${ }^{b}$ \\ a Student, Tarleton State University, 1341 Garfield Ave. Stephenville, TX 76401. \\ b Professor, Tarleton State University, E-mail: stanley@tarleton.edu \\ *Corresponding author's email address: jacob.woolridge@go.tarleton.edu
}

\section{A R T I C L E I N F O}

Received: 29-06-2016

Accepted: 10-07-2016

Available online: 19-07-2016

Keywords:

Consumerism;

Family; Households;

McDonaldization;

Maslow's hierarchy.

JEL Classification:

D02; D10; D91; J12; P36

\begin{abstract}
A B S T R A C T
Using data collected over three years and mimicking the methodology of Arnold et al. (2012) in Los Angeles, a study in Texas was conducted in which 66 families opened their homes and allowed video, survey data, and pictorial evidence to be collected. These data are used to determine if McDonaldization has spread from the public sphere into the private sphere by determining if the four factors of McDonaldization: predictability, calculability, efficiency, and control are present, and if so, in what ways they are represented. Ultimately, every single household studied showed instances of all four factors of McDonaldization, thus heavily supporting the hypothesis that McDonaldization has encroached into the private sphere. This phenomenon will be explained by using McDonaldization either as a rational means to pursue individualistic self-actualization as described through Maslow's Hierarchy of Needs or as a means by corporations to extend their own factor of control into the private sphere and thus influence consumers. Finally, the fifth factor of McDonaldization, irrationality emerging from rationality, was examined with examples provided.
\end{abstract}

This is an open access article under the terms of the Creative Commons Attribution License 4.0, which allows use, distribution and reproduction in any medium, provided the original work is properly cited.

DOI: http://dx.doi.org/10.18533/rss.v1i7.49

ISSN: 2378-8569 (Print), 2378- 8550 (Online)

McDonaldization, first described by Ritzer (1993), describes the process by which rationality is used to streamline processes to the point of irrationality. This theory draws heavily from Weber's (2003; 1905) Iron Cage of Irrationality and describes the process by which rationality grows to the extreme of irrationality. However, while this process is heavily documented in several corporate and macro-sociological processes, particularly within the fast-food industry, there has not been any extensive research to determine the spread of McDonaldization into the private sphere primarily because of the theoretical barrier between the public and private spheres described by Habermas (1985).

Our study draws upon the methodology of Arnold, Ragazzini, Graesch, and Och's (2012) study in Los Angeles in order to investigate the presence, or lack thereof, of McDonaldization within homes in Texas. To determine this process, evidence of the four primary factors of McDonaldization were analyzed. The presence of all four of these factors of McDonaldization within a single household indicates the presence of McDonaldization within the particular household.

Upon completion of the study, all sixty-five houses analyzed showed the presence of McDonaldization and each also exhibited several instances of irrationality that ultimately arises from McDonaldized systems according to Ritzer (1993). 


\subsection{McDonaldization}

McDonaldization is a symbolic interactionist approach originally proposed by George Ritzer in his paper, The McDonaldization of Society (1993). In this analysis, Ritzer analyzes the current corporate system in America and reduces several industries to four primary characteristics that have been adapted from the fast-food chain, McDonald's. These factors include predictability (the expectation that products will be uniform in quality), calculability (the tendency to emphasize quantity over quality), efficiency (the optimal way to achieve a task), and control (the use of environment and policies to control the consumer in ways that are beneficial to corporations). However, while studies have repeatedly shown this model to be accurate of the United States corporate structure, and the public and private sphere are becoming increasingly merged (Seligman, 1998), this model does not accurately apply to the private sphere and family model primarily because while the family does exist as an economic unit, the family's goal is not to produce products and earn a profit. Thus the factors of McDonaldization cannot be applied without a significant strain of analogy. Because of this, there has not been a comprehensive study that applies the McDonaldization model to the family in order to investigate whether McDonaldization has actually extended into the private sphere and, if so, in what ways.

This migration of McDonaldization outside of the realm of strictly profit-making was recorded by Nicholson (2015) in the library system and Bohm (2006) in the judicial branch of the United States Justice System and the potential for the presence of McDonaldization was recorded by Timimi (2010) in the connection between the number of extracurricular activities children have and their (parent) evaluated success in the public sphere.

Thus, this paper will analyze the McDonaldization model and determine if McDonaldization has extended fully into the private sphere and, if so, in what ways.

\subsection{Repurposing of the McDonaldization model}

Ritzer (2015) describes McDonaldization as a model that allows large corporations to maximize profit while minimizing expenses. However, because the family is not a purely economic unit, the original four aspects of McDonaldization need to be adapted in order to avoid the fallacy of strained analogies (Habermas, 1985). Thus, predictability of product and staff interactions was repurposed to focus more upon the predictability of individual family member's behavior and location. This is primarily done through the practice of routines, which are communicated by using calendars and schedules and realized in the expression of regularly occurring events such as bedtimes, dinner times, and attendance of regulated extracurricular activities. Calculability was repurposed to identify the accumulation of multiple statuses and the higher emphasis placed upon a well-rounded individual rather than a singular expertise. However it is not enough to merely accrue these statuses. They must also be physically actualized through decorations, collections, or other objects in the house that allow each status to serve as a testament to the owner. Efficiency retains much of its initial properties given to it by Ritzer. However rather than purely analyzing the optimal method to achieve the proper service, this study investigates other methods of optimization such as space utilization, food preparation, and food consumption. Finally, control will be altered from its original model to primarily act as the enforcement mechanism of predictability and efficiency rather than an explanation for increased reliance upon machines. Thus, many of the variables associated with these two factors, by virtue of existing functionally, also represent a measure of control.

\subsection{Predictability}

In the original McDonaldization model, Ritzer (2015) defines predictability as the ability of the consumer to accurately expect certain standards of the products being created. While this idea of predictability is surely used within the family, it is not predictability of a product that is expected, but rather, the entire family's and individual family member's behaviors. Thus, routines, or the active predetermination of activities that are explicitly stated and communicated to all other members of the family, emerge.

Through routinization, manifest functions arise which allow the family to act and coordinate their activities according to schedules that have been explicitly set and communicated. However this has also turned predictability into a social more of the family, explaining why deviance from expected patterns, such as playing hooky from school, have increased in importance over recent decades and explains how family members have developed rituals, such as morning rituals and holiday traditions, in order to keep up with a faster paced, goalsoriented American society (Collins, 2004).

\subsection{Calculability}

In the original McDonaldization model, Ritzer (2015) noted that consumers began to forego the quality of a given product and instead focus on the amount of a product that a consumer can purchase for a given amount of money. 
This 'quality vs. quantity' phenomenon sparked the production of products that sacrificed quality in order to assure a massive output of cheaper, lesser quality goods and food.

Using a corollary, the active support and encouragement of American children to participate in extracurricular activities is often seen as largely beneficial to the children's growth and development as well as their future wellbeing (Noonan, David, Sieder, Jordan, \& Peraino, 2001). However, this fascination with extracurricular activities causes parents to push their children to pursue a large number of varying extracurricular activities rather than focusing on and becoming masterful of one particular activity, populating this same quantity over quality mentality (Gager, Sanchez, \& Demaris, 2009).

However, calculability is not limited to the children's' extracurricular activities, but also resides in the usage of decorations to adorn the home. These decorations, in addition to serving as a way to personalize the home, may also act as a way to display garnered statuses (Norris, 2011). Even collections, which hypothetically represent objects of arbitrary importance, when displayed are used to convey a personal status about the owner. Thus, we hypothesize that if certain decorations and collections attribute certain statuses, and if calculability has creeped into the private sphere, then certain positive statuses will be reinforced repeatedly throughout the house and will manifest in copious amounts of decorations that fit into a motif that aligns with the status meaning to be conferred. Furthermore, following the quality of calculability, rather than displaying one instance of a particular status, decorations portraying that status will be superfluously shown throughout the house and, when taken as a whole, all of the decorations will ultimately represent a vast number of statuses.

\subsection{Efficiency}

Efficiency is typically used in the McDonaldization model to refer to the optimal method of achievement, or the cost-benefit analysis of picking a certain product or procedure in preference to other options (Ritzer 2015).

The McDonald's model relies on busy, working parents to make the decision to sit in line at McDonald's for two minutes and get a burger which everyone in the family will enjoy, or loading kids in the car, driving to the grocery store, getting proper ingredients (do not forget the condiments), paying out, loading the groceries and kids back into the car, driving home, unloading kids and groceries, cooking, preparing, and serving, then cleaning up after everyone is done eating. However, because the family model does not mirror the market driven mentality of industry, this factor needs to be repurposed to account for the rationalization of people. Thus, the presence of efficiency within the family would most likely be marked by the presence of quick, easy meals that feed several people and effective use of space within the household for the storage of possessions. These things would allow for efficient use of time and resources during meals and allow for the most rational allocation of space in the household, thus ensuring not only effective use of all available space in the household, but also ensuring the most efficient way to portray the calculability factor of McDonaldization (see 4. Calculability section).

\subsection{Control}

In Ritzer's (1993) original model, control is used to describe the process by which corporate owners manipulate their customers to perform various tasks such as discarding their own trash or leaving the restaurant quickly to make room for new customers. This establishment creates a division of labor which requires the formation of a hierarchy; the necessary condition for any organization (Schwartz \& Scott, 2012). Even communes, which Marx (1871) defines as a working body that has the power of all three branches of government (executive, legislative, and judicial) in order to make all of the logistical decisions for the larger community, indicates that some form of leadership is required and in Grundrisse, Marx $(1971 ; 1857)$ explicitly lists the head of a household as the leader of a commune, thus establishing organization through hierarchy within the home. This hierarchy is usually expressed through co-paternalism however patriarchy is generally expressed more often than matriarchy (Carlson, 2007). The existence of a hierarchy in itself implies a difference between the moderator and the moderated, the law-maker and the law-abider, the master and the slave and so demands that while a symbolic interactionist approach must be used in order to derive meaning and determine why and if McDonaldization applies within the family, Marx's conflict theory must inevitably be used to investigate how these meanings and rationalizations are implemented.

Thus, the final characteristic of Ritzer's McDonaldization method (2015), control, is seen within the family as the enforcement mechanism that allows for the existence of McDonaldization. While the other three factors of McDonaldization may be present, these phenomena as symbolic concepts represent little more than suggestions without the power of enforcement. Thus, we hypothesize that the control factor acts similarly to the executive branch in a government; the enforcement of social norms and McDonaldization within the home. 


\subsection{Maslow's Hierarchy}

The reason McDonaldization exists is to allow an institution to rationalize a set of processes and make it more efficient in order to achieve its purpose (Ritzer, 2015). However, any institution without a purpose would have no need to rationalize any processes; if there is no goal with which to reach more efficiently, there is no need for McDonaldization. Thus, if McDonaldization exists within the household, it implies that it is being used to reach an ultimate goal.

To determine a possibility of this goal, we will draw from Maslow's Hierarchy of Needs (2013). This hierarchy has been used in several psychological and philosophical studies to determine the motivation behind human behavior. To do this, Maslow divided human needs into several categories. First, Maslow identifies physiological needs, which he defines as things that a human body physically needs to survive such as food, water, and sex. Next, Maslow identifies security, which he defines as the things needed such as clothing and shelter to ensure the continued possession of physiological needs. Maslow then describes the next category as belonging, which he defines as the need for human interaction. Finally, Maslow concludes the deficiency needs (the needs all people require for basic survival) with esteem, which he defines as both self-respect and obtaining respect from others. At the acme of the hierarchy, Maslow determined that the ultimate goal of humanity as self-actualization, which he defines as the goals which are pursued solely for itself, such as leisure or happiness (Maslow, 2013). Since humanity's ultimate goal is obtaining the deficiency needs in order to achieve self-actualization, and American households have achieved these deficiency needs, then we hypothesize that the goal of the McDonaldization process in the family is to allow each member to reach self-actualization in the most rational method possible.

Maslow's hypothesis of humanity pursuing self-actualization has been modeled repeatedly and confirmed at the macro-level (Hagerty, 1998). However groundbreaking research conducted by Sumerlin and Norman (2010), which describes how even lower classes of American society actively pursue self-actualization, demonstrates how this pursuit is also shown in micro-society. Research conducted by Foroohar (2012) describes the standard of living in a significant number of American households as above average despite stagnant wages since the 1970's indicating that, on average, Americans have achieved a significant number of their deficiency needs (Meyerson, 2013). Thus, because Maslow's Hierarchy applies at the micro-sociological level and because families have achieved their deficiency needs, this study will investigate McDonaldization as a means to pursue selfactualization.

Self-actualization is difficult to measure due to its largely vague and arbitrary nature. Thus, in this study, we define self-actualization in terms of Marx's (1848) concept of species being, which describes the ideal state of humans as being able to socialize, perform creative activities, and acknowledge transcendent beauty. In the Communist Manifesto, Marx (1848), describes capitalism as the primary reason inhibiting species being from becoming actualized. However, even without the profit motive exhibited by corporations, if the ideal human state is species being, then it makes sense that this state would be pursued at all times, not only whenever the public sphere is entered. Thus, the motive of humanity is to reach species being, otherwise known as self-actualization, and because self-actualization is a worthy goal to reach, humans try and reach that goal as quickly and efficiently as possible, thus the emergence of McDonaldization within the household.

\subsection{Irrationality from rationality}

Drawing from Ritzer's (1993) original model, despite the extreme rationalization of processes, irrationality will inevitably emerge. While not formally a factor of McDonaldization, irrationality emerging from rationality was the side effect measured by Ritzer (1993). These irrationalities often result from an over-bureaucratization of simple procedures or a measure of cognitive dissonance between means and ends. Thus, any system which uses the McDonaldization model, including the family, will exhibit certain characteristics that emerge as irrational.

These instances of irrationality are widely varied and range from standardized testing that causes high school students to graduate with a dearth of knowledge instead of creating a universal standard of learning, to perhaps the most extreme example of irrationality, which occurred during World War II when a quest to create an ideal, utopian society ultimately caused the creation of the atomic bomb, the very weapon that made the mass extinction of man possible.

Irrationalities that emerge in the family will most likely err on the side of milder cases. However it must be noted that any situation in which children are affected also affects the future potential of the human race and so any deficiencies that are caused by these irrationalities could, as in the case of World War II, cause potentially dangerous and destructive results. 


\subsection{Methods}

In the spring of 2013,2014, and 2015, students at a Texas university collected data on households ( $\mathrm{N}=66)$ using similar methodological techniques to those used by Arnold et al (2012) in Los Angeles. Each parent conducted a video tour of the household individually and a video interview of both parents with a minimum of 75 minutes of footage per household. In addition, survey data were gathered by each parent individually $(\mathrm{N}=132)$, and at least 125 pictures of each household were collected.

Pictorial evidence for extensive use of calendars and other daily planners in order to coordinate familial activity was used to verify the presence of predictability. Also, the display of collections was used to show predictability by giving the displayer a reasonable expectation of what to expect when they receive a gift. Additionally, survey data, particularly V. 21 (number of hours worked per week), V.34 (children's bedtimes), and V.49 (children participation in extracurricular activities) was used. The presence of these items and specific answers from the given questions will be identified as and associated with routines, thus reflecting active work by the family to pursue predictability.

Survey data, particularly V.49 (does the child participate in extracurricular activities) and V.50 (if so, which extracurricular activities) was used to determine the presence of calculability. In addition, pictorial evidence was used to investigate both the number of decorations and the kinds of decorations used throughout the house. Certain themes, such as religion, were identified and the number of times these themes were used throughout each individual house were analyzed along with the display of participation certificates and trophies to confirm the presence of calculability. In addition, the display of collections is used in a similar way as the use of specific decorations: to display a particular status. Thus, pictorial evidence was also scoured to determine the presence and displaying of collections. Finally, the realization that clothing is often used as a means to display a wide number of statuses is taken into account and thus, pictorial evidence of crowded closets was also used to determine the presence of calculability.

In the household, we hypothesize efficiency to take a similar model to the cost-benefit analysis used in the fast food industry, with frozen foods and easy-to-prepare meals taking precedence over raw ingredients that take up large amounts of space and require time and energy to prepare. In addition, pictorial evidence depicting the conservation of space through the use of storage bins as well as the presence of calendars was used to determine the presence of efficiency. Survey data from questions V.52 (how often groceries are bought), V.53 (where are groceries bought), V.59 (how much processed food is purchased), V60 (how often the family eats at a restaurant), V.61 (how often the family eats fast-food), and V.65 (how much food is wasted) were used to determine the presence of calculability. Finally, the use of collections represents a level of efficiency by providing the subject a quick answer to what should be given when a gift is required and thus, the presence of collections is indicative of the presence of efficiency.

Survey data, in particular V.34 (children's bedtimes) and V.50 (kinds of children's extracurricular activities) have been used to determine the presence of control. Extracurricular activities can represent regulated activities (such as a referee-controlled game) or unregulated activities (such as reading). By analyzing V.50, the use of regulated or unregulated extracurricular activities will determine whether control is being exerted over the leisure time expressed by children in the household. Additionally, pictorial evidence of calendars, chore charts, and homework check boxes expresses a measure of control by assuming that all of the events are being enforced and thus, their presence was used to indicate the control factor. The use of physical restraints, such as gates, safes, or height, was also used to indicate a measure of control by simply eliminating the option of choice from those who do not have the proper 'requirements' (such as height or the key). Finally, interview data was used to analyze the presence and kinds of controls used on children's electronic devices. The use of controls will be used to determine the presence of control in the household and the kinds of control will be used to determine the extent and forms that that control takes.

\subsection{Findings}

The findings of our study reveal a homogenous makeup of families. The families studied were comprised of 66 heterosexual couples ranging from 21 to 55 years of age with a median age of 41 . The average length of marriage amongst the couples was 13 years. Almost $95 \%$ of the respondents to the study self-reported their race as "white" with $62 \%$ self-identifying as "middle class". Geographically, the respondents were mainly focused in central Texas with a majority in Stephenville and the Dallas/Fort Worth area, however samples spanned 363 miles on an east/west axis and 341 miles on a north/south axis. 
When investigating the pictorial evidence of predictability, seventy-three instances were found, representing $59 \%$ of the families studied. Most of these pictures depict calendars and reminders, which focused around the refrigerator and other public areas, and collections which were displayed throughout the house. The displaying of these calendars in public areas supports the hypothesis that the primary purpose of predictability is establishing and communicating routines. Further, in the surveys studied $(\mathrm{N}=132), 100 \%$ of the respondents showed specific answers to V.21 (number of hours worked), 93\% gave specific answers to V.63 (dinner times), and 95\% gave specific answers to V.34 (children's bedtimes) and V.49 (children's extracurricular activities), establishing clear routines that the family structure revolves around. Thus, evidence of these routines in tandem with the pictorial evidence depicting calendars and other routine-setting devices show overwhelming support for the hypothesis that predictability as a factor of McDonaldization exists within the households studied (See Table 1 and Figure 1).

\begin{tabular}{lr}
\hline & Table 1 \\
\hline Calendar & \\
Collections & $50 \%$ \\
Bedtimes & $12 \%$ \\
Dinnertimes & $95 \%$ \\
Extracurricular & $93 \%$ \\
Work Hours & $95 \%$ \\
\hline
\end{tabular}

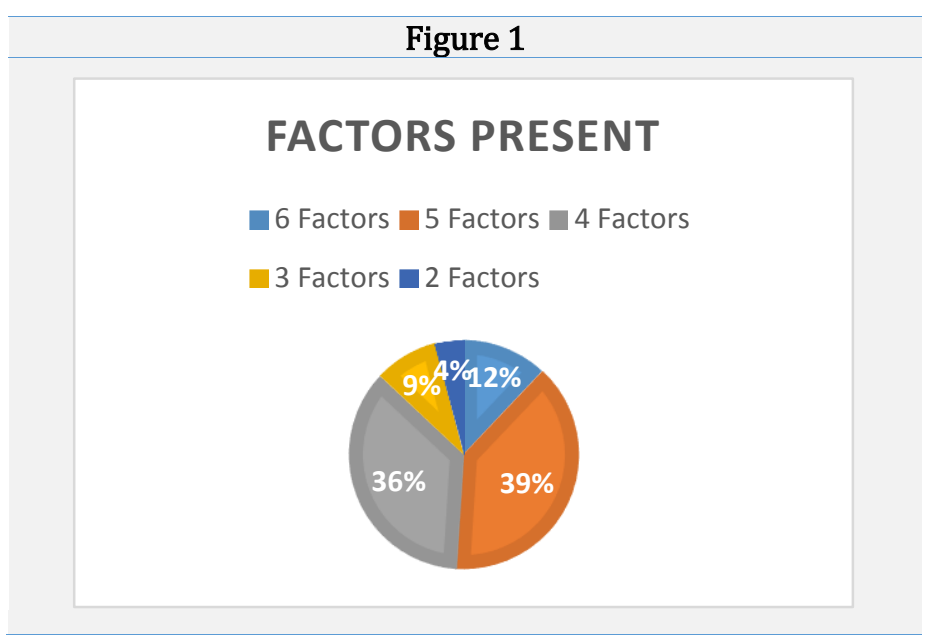

When investigating the pictorial instances of calculability, 235 instances were recorded, representing $86 \%$ of families studied. This pictorial evidence was primarily shown through the amount of bulk foods that were purchased, the collection of particular items, the amount of decorations that were accumulated and displayed, and the amount of clothing that subjects had in their closets. When the pictorial evidence was analyzed, children's rooms were the primary places where awards and achievements were displayed, however several of the video tours by both parents depicted both spouses providing detailed reasons as to why each decoration was chosen, assigning intricate symbols to decorations and embellishing each with a memory or personal statement, indicating that even in the house at large, parents are prone to exhibiting calculability just as much as children. For example, pictorial evidence revealed two common motifs represented throughout all Texas households; one associated with religious crosses and scriptures, which was found 234 times in fifty-two households and one associated with animals, particularly animal heads, appearing 149 times in forty-five families (See Figures 2 through 7).

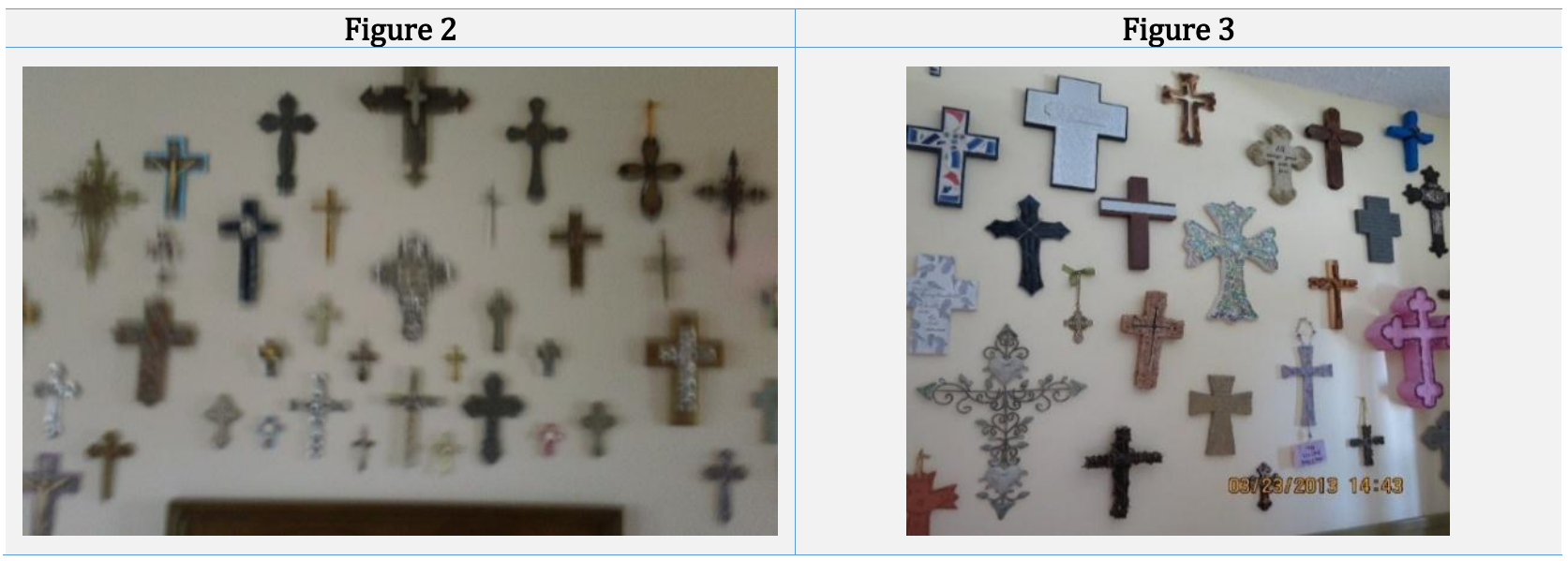




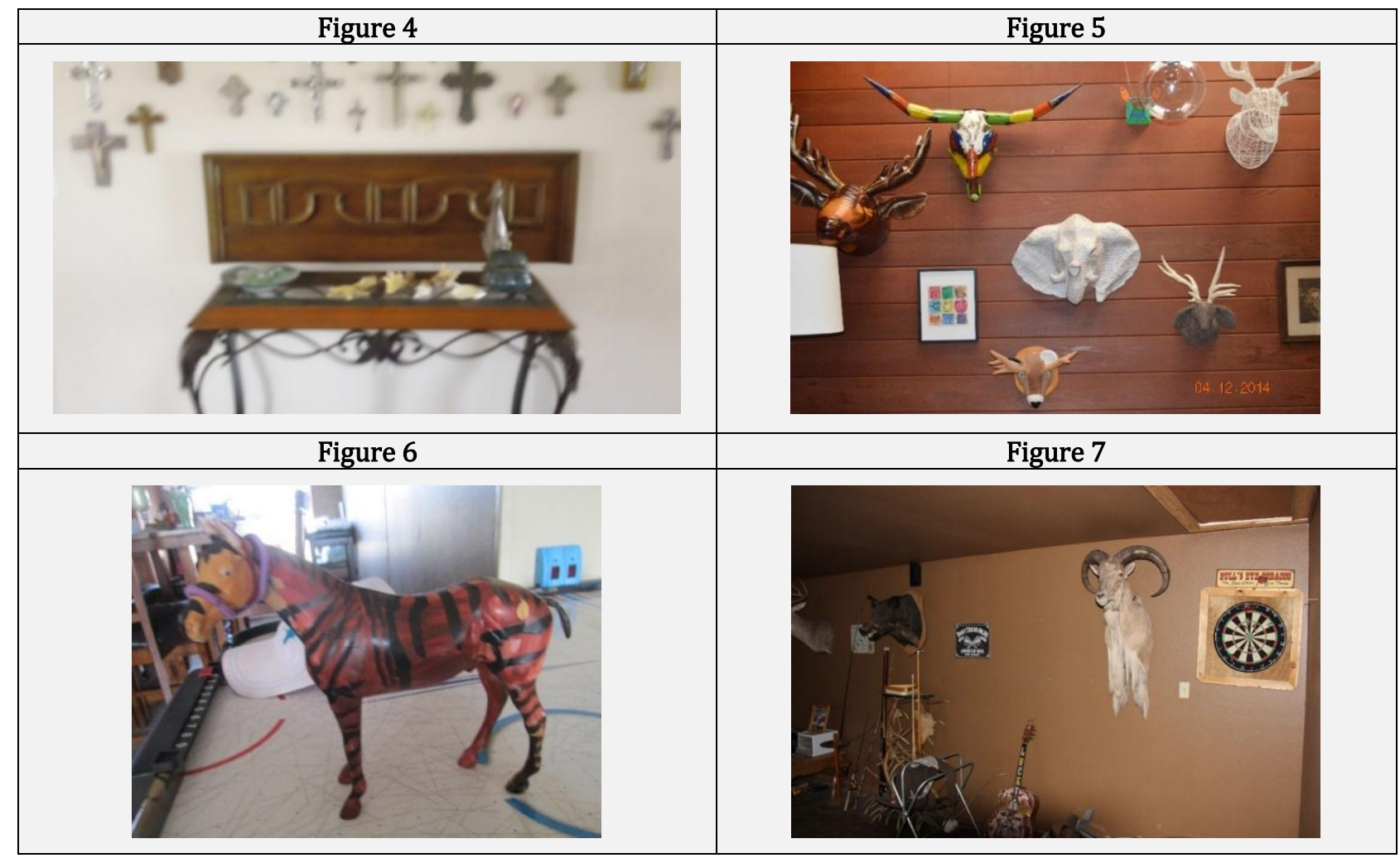

The survey evidence for calculability was overwhelming, with $86 \%$ of the surveys (N=132) showing an affirmative answer to V.49 (children's extracurricular activities). Of these 108 surveys, 75\% record participating in more than three different extracurricular activities, indicating not only the degree to which calculability has invaded, but also showing that even from an early age, parents push children to value the number of activities that they perform. Thus, the survey data heavily support the presence of calculability in the households studied and the pictorial evidence reveals that not only a vast majority, but essentially every single case has at least one sign of calculability, indicating that even if there is insufficient evidence to determine if the other three factors of McDonaldization exist in Texas households, that there is one factor present shows that McDonaldization has occurred in Texas households to some degree (See Table 2 and Figure 8).

\begin{tabular}{lr}
\hline & Table 2 \\
\hline Bulk Foods & \\
Collections & $98 \%$ \\
Decorations & $12 \%$ \\
Overflowing Closets & $100 \%$ \\
Religious Motif & $100 \%$ \\
Animal Motif & $79 \%$ \\
Extracurricular & $68 \%$ \\
\hline
\end{tabular}

Figure 8

\section{FACTORS PRESENT}

$\square 7$ Factors $\square 6$ Factors $\square$ Factors $\square 4$ Factors $\square 3$ Factors $\square 2$ Factors

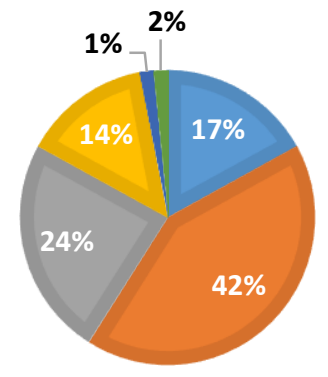


When investigating the pictorial instances of efficiency, 194 instances were recorded, representing $86 \%$ of the families. This pictorial data was primarily found in refrigerators and freezers where vast arrays of easily stored and prepared foods were kept. Significant evidence of efficiency was also found throughout the house and in multiple rooms in the form of collections of particular items, which not only allow for the display of a particular status (calculability), but also engender a level of efficiency and predictability during particular times of the year when gifts are expected (it is much easier to buy for someone and predict what will be received if there is a collection that needs to be added to). The presence of calendars represents efficiency by effectively communicating routines without the need to verbally convey information. Use of storage bins and other storage devices throughout the house also indicate a high level of efficiency by creating areas of organization and facilitating an efficiency of space. Ninety-eight percent of the survey respondents report buying from one-stopshop stores (V.53) and $87 \%$ of respondents report wasting less than $20 \%$ of the groceries that they do buy (V.65), indicating high rates of efficiency, particularly when food is involved. The establishment of routines (predictability) also augments efficiency by minimizing the necessary processes of coordination; it is imparted implicitly that certain things need to be done at certain times and so the need to actively communicate to every house member what needs to be done is abolished. Thus, from the survey data and pictorial evidence of collections, storage bins, and pre-prepared food, efficiency is a prominent factor of McDonaldization within the household (See Table 3 and Figure 9).

\begin{tabular}{ll}
\hline \multicolumn{2}{c}{ Table 3 } \\
\hline Frozen Food & $58 \%$ \\
Collections & $12 \%$ \\
Storage Bins & $50 \%$ \\
1-Stop-Shop & $98 \%$ \\
Waste less than 20\% & $87 \%$ \\
Calendars & $50 \%$ \\
\hline
\end{tabular}

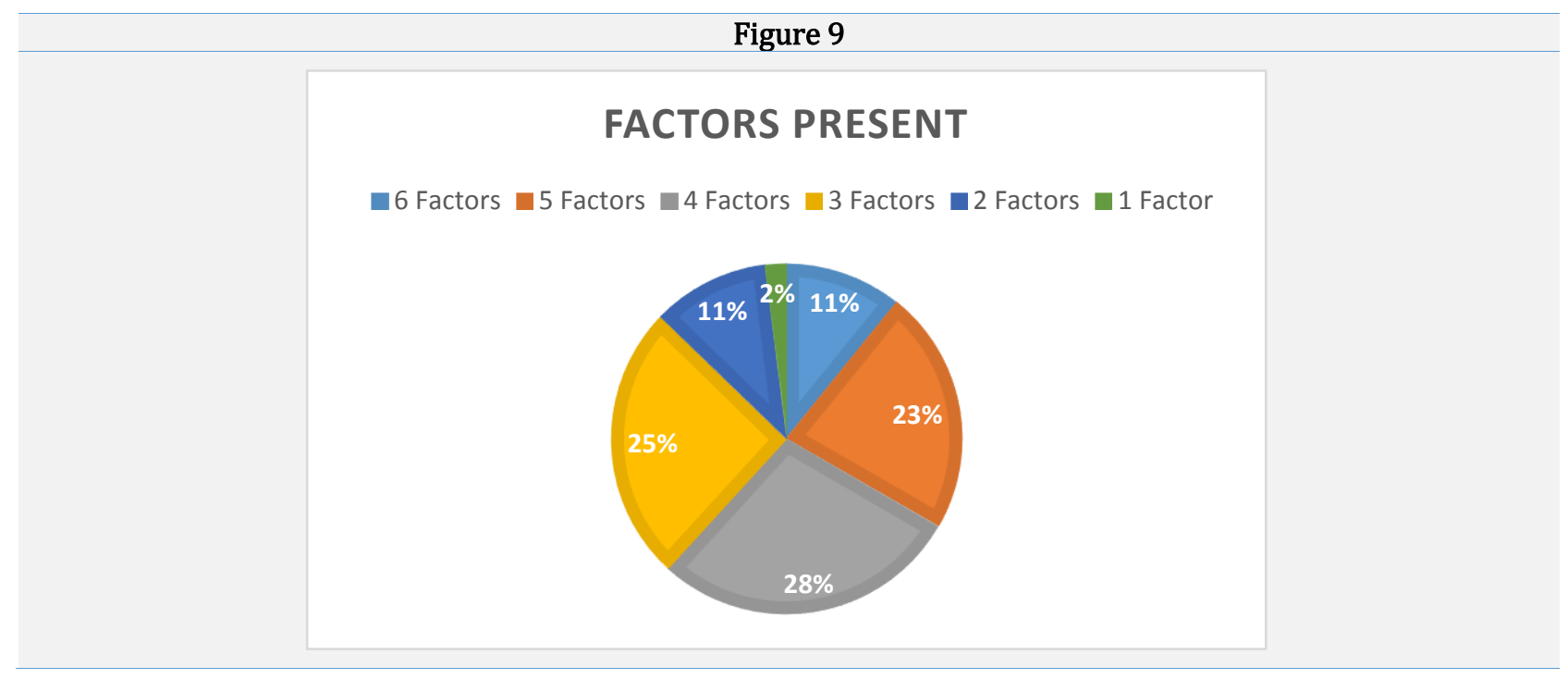

When investigating the pictorial evidence for control, 72 instances were recorded, representing $53 \%$ of the families. These instances primarily refer to chore charts, calendars, or homework check boxes, indicating a sense of control over actions that an individual needs to take. Some examples of control however, such as gates, act in the opposite way to prohibit certain actions from being taken and effectively remove the decision-making process from the individual. Control also works alongside predictability in that whenever there is a routine or a schedule to meet, there is a means to enforce the measures necessary to meet that schedule or routine. Some of these explicit manners of control are not new, but rather an extension from functional families in the past. However these observations are, for the first time, viewed alongside survey responses, particularly to V.50 (what kinds of extracurricular activities do your children participate), which indicate that nearly every form of extracurricular activity that the respondent's children participate in, such as sports and individualized lessons, rely heavily on controlled and monitored activities, showing that even leisure time is conducted in specific settings. Thus, it is clear from observing the impact that explicit controls, such as bed times and physical restraints, alongside implicit controls, such as the forms extracurricular activities, that control is present in the household (See Table 4 and Figure 10). 


\begin{tabular}{|c|c|}
\hline \multicolumn{2}{|c|}{ Table 4} \\
\hline Calendars & $50 \%$ \\
\hline Electronic Controls & $15 \%$ \\
\hline Physical Restraints & $14 \%$ \\
\hline Extracurricular Type & $100 \%$ \\
\hline Check Boxes & $17 \%$ \\
\hline
\end{tabular}

Figure 10

\section{FACTORS PRESENT}

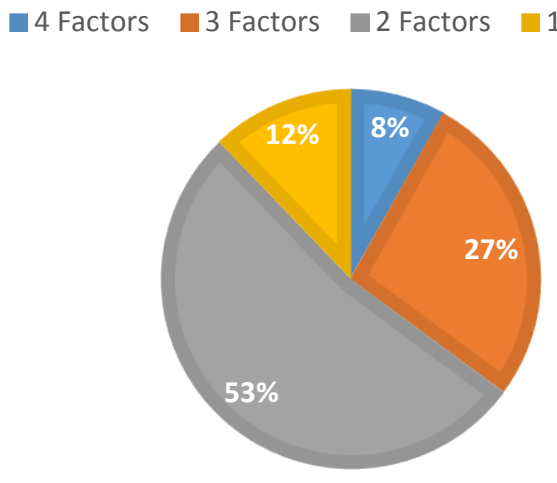

With each of the four factors: efficiency, predictability, calculability, and control identified and recorded, every single household in the study displayed a degree of McDonaldization. This evidence strongly supports the hypothesis that McDonaldization has encroached upon the private sphere of the family.

\subsection{Irrationalities}

With all cases exhibiting characteristics of McDonaldization, there were also a few distinct instances in which irrationality emerged. For instance, despite every household displaying some form of moderate control, only $15 \%$ of respondents record controlling their children's electronic devices. Which means that $85 \%$ of the families do not use any kind of control and the $15 \%$ that do only restrict the amount of time their children spend on their electronics, not the content. Thus, despite high levels of control exhibited in specific, public events, very little control is shown where there is a severe potential for abuse.

$50 \%$ of respondents use storage boxes, a concept that is in itself irrational ${ }^{1}$, which not only support efficiency as a factor present in the household, but also reveals evidence that shows how an entire corporate industry has opened specifically designed to maximize the space used by households, showing a very real example of how the corporate world is profiting from the expansion of McDonaldization into the private sphere and perhaps offering an example of how corporations could potentially influence control of the private sphere through the manipulation of product placement, design, and advertising.

Finally, assuming self-actualization is the goal of McDonaldization, the data suggests that despite the vast number of factors that families are utilizing, self-actualization is not actually being achieved. Respondents replied that they work an average of 45 hours per week and sleep an average of 7 hours each night. Therefore, in a standard 5-day week, respondents have 8 hours per day with which to pursue their activities. However when taking the multitude of things that respondents have to do including shopping, taking children to extracurricular activities, grooming, childcare, cooking, and cleaning, there is little time for themselves. In fact, $27 \%$ of respondents indicated that they had no time for themselves (V.68) and the average respondent only went outside an hour each day. Despite the assumed contentedness that arises from self-actualization, $57 \%$ of respondents indicated that they have higher than average levels of stress, indicating that the need for money, the shopping necessary to promote calculability, the strict routinization that makes predictability possible, the fast, frozen food that makes efficiency possible, and the measures taken to maintain control all work against the ultimate end goal: to pursue their individual interests to the fullest of their ability and achieve self-actualization.

\footnotetext{
1 There is too much stuff in the house, so I am going to go to the store and buy something to put the other things that I have bought into so that I can have more room to buy more stuff.
} 
Thus, while the reasoning exists that McDonaldization allows for quick and efficient completion of mandatory activities so that self-actualization can be pursued, the data show that because of the effort needed to perpetuate McDonaldization's factors of calculability and control, more work is being done and actually preventing selfactualization, even though there may be less time actually spent at their job.

\subsection{Discussion}

The methods used in this study were similar to Arnold et al's (2012). However some aspects from the original study have been amended due to technological restrictions; specifically, blood testing to determine stress levels and room monitoring technology to determine room usage throughout the day. Both of these variables were replaced with additional questions in the survey. Stress levels were measured using a Likert scale (V.35) and selfevaluation of the respondent through several attributes such as which room is used most often by the respondent (V.37), whether the respondent had a sanctuary room in the household (V.69), and which room is used most by the family as a whole (V.33) was used to determine room usage.

The tracking of McDonaldization into the home is significant in that it stipulates that the corporate model is slowly encroaching itself into family life: a domain where it has not been yet in history. This encroachment has the potential to represent one of two possibilities: either that corporations are on the correct path to finding the quickest and easiest method of achieving a goal and other social organizations are seeking to mimic them, or that they have grown so powerful that in their own McDonaldization model, the control factor has extended from their own, public domains into the private domains of the households of their consumers. This first hypothesis is supported by the overall success of the free market system and the rapid growth of technology and innovation within it, however it also requires the premise that McDonaldization exists to pursue a goal, reinforcing the idea of using Maslow's Hierarchy as the underlying philosophical principle for determining the underlying goal in modern Texas families because just as corporations without the profit motive would not use McDonaldization, families without a common goal, such as self-actualization, would not need McDonaldization because there would be no reason to apply it. The second hypothesis is more insidious and implies that despite Habermas' (1985) interpretations of distinct public and private spheres, McDonaldization exists as a force that could potentially breach this difference and act as a method through which the corporate model comes to resemble a predator-prey model with McDonaldization simply being the latest advancement in evolution to capture its prey (consumers) and garner nourishment (the consumer's money).

That families would allow McDonaldization into their household and even willfully choose to accept it shows that the ultimate goal of McDonaldization, whether it be for corporate profit or achieving a specific goal, is important. But the choice to accept McDonaldization is in itself important. Ultimately, there are many ways to achieve selfactualization within the household and so because families are choosing McDonaldization, it entails that it offers something that is not being offered through other alternatives. Thus, in addition to achieving self-actualization, perhaps it is also the model itself that is valuable to families; it is the factors present that, in addition to fulfilling the ultimate goal, also supply families with a healthy amount of functionalism and thus work to combat anomie that would otherwise engulf families living in a modern, fast-paced, and dispassionate American culture.

The collection and display of items associated with the two primary motifs, animals and religion, could be used to support a hypothesis that these two statuses seem to be perceived as master statuses when compared with other statuses of similar natures. The reasoning for this could be through an implicit implication that an abundance of one thing, such as religious items, means an increased amount of religiosity, which is considered beneficial and the accumulation of animals could represent the expression of free time spent hunting (as opposed to doing housework) and thus could represent a status not of a skilled hunter, but rather a person who, despite the irrationalities of McDonaldization, still managed to achieve self-actualization in some aspect. Thus, while less prevalent, perhaps all other collections fulfill one of these purposes: either explicitly conveying a degree of a status or merely conveying a 'success story' of the McDonaldization model in the household.

Finally, the extension of McDonaldization into the private sphere potentially sets the precedent for other traditionally public social phenomena extending into the private sphere and could become the gateway study for traditionally macro-sociological aspects being applied at the micro-sociological level. This precedent, beyond immediately realized applications, also could potentially be used to grow or shrink other theorems to better suit both micro (diodes) and exponentially macro (international relations) situations.

\section{References}

Arnold, J.E., Ragazzini, E., Graesch, A.P. \& Ochs, E. (2012) Life at home in the twenty-first century: 32 families open their doors. Los Angeles, CA: Cotsen Institute of Archaeology Press 
Bohm, R. M. (2006). "McJustice": On the McDonaldization of Criminal Justice. JQ: Justice Quarterly, 23(1), 127146. http://dx.doi.org/10.1080/07418820600552576

Carlson, A. (2007). The Natural Family Dimly Seen Through Feminist Eyes. Modern Age, 49(4), 425-433

Collins, R. (2004). Interaction ritual chains. Princeton, NJ: Princeton University Press

Foroohar, R. (2012). More Jobs, Less Pay. Time, 180(17), 23. http://dx.doi.org/10.1515/9781400851744

Gager, C. T., Sanchez, L. A., \& Alfred, D. (2009). Whose Time Is It? The Effect of Employment and Work/Family Stress on Children's Housework. Journal of Family Issues, 30(11), 1459-1485. http://dx.doi.org/10.1177/0192513X09336647

Habermas, J. (1985). The theory of communicative reason: Reasoning and the rationalization of society. (T. McCarthy, Trans.). Boston, MA: Beacon Press. (Original work published 1981).

Hagerty, M. (1998). Testing Maslow's hierarchy of needs: National quality of life across time. Social Indicators Research, 46(3), 249-271. http://dx.doi.org/10.1023/A:1006921107298

Marx, K. (1871). The Civil War in France. (E. Truelove Trans.). London, England: Bristol Selected Pamphlets. (Original work published 1871).

Marx and Engels. (2014). The Communist Manifesto. Samuel Beer (Ed.). [Kindle version]. Retrieved from amazon.com. (Original work published 1848).

Marx, K. (1971). The Grundrisse. (D. McLellan Trans.). New York City, NY: Harper \& Row. (Original work published 1857).

Maslow, A. (2013). A theory of human motivation. Seaside, OR: Rough Draft Printing. (Original work published in 1954).

Meyerson, H. (2013). The Forty-Year Slump. American Prospect, 24(5), 40-54.

Nicholson, K. P. (2015). The McDonaldization of Academic Libraries and the Values of Transformational Change. College \& Research Libraries, 76(3), 328-338. http://dx.doi.org/10.5860/crl.76.3.328

Noonan, D., Sieder, J. J., Peraino, K. (2001). Stop Stressing Me. Newsweek, 135(5), 55.

Norris, T. (2011). Consuming schools: Commercialism and the end of politic. Toronto: University of Toronto Press

Ritzer, G. (2015). The McDonaldization of society: $8^{\text {th }}$ edition. Thousand Oaks, CA: Sage Publications. (Original work published 1993).

Schwartz \& Scott. (2012). Marriages and families: Diversity and change. Upper Saddle River, NJ: Pearson.

Seligman, A. B. (1998). Between Public and Private. Society, 35(3), $28-36$. http://dx.doi.org/10.1007/BF02686133

Sumerlin, J.R., \& Norman, R.L. (1992). Self-actualization and home-less men: A known-groups examination of Maslow's hierarchy of needs. Journal of Social Behavior and Personality, 7, 469-481.

Timimi, S. (2010). The McDonaldization of Childhood: Children's Mental Health in Neo-liberal Market Cultures. Transcultural Psychiatry, 47(5), 686-706. http://dx.doi.org/10.1177/1363461510381158

Weber, M. (2003). The protestant ethic and the spirit of capitalism. Mineola, NY: Dover Publications. (Original work published in 1905).

Wilson, E. (1975). Sociobiology: The new synthesis. Cambridge, MA: Belknap Press of Harvard University Press. 